\title{
COMPARATIVE ORGANIC GEOCHEMICAL STUDY OF CRETACEOUS RESERVOIRS OF ZUBAIR OIL FIELD, SOUTHERN IRAQ
}

\author{
${ }^{1}$ Mina Allah M. Hatif*, ${ }^{1}$ Muwafaq F. Al-Shahwan and ${ }^{2}$ Abdulla A. Al-Yaseri \\ ${ }^{1}$ Department of Geology, College of Science, University of Basra \\ ${ }^{2}$ Basra Oil Company \\ *E-mail: minaallah.mohammed@hotmail.com \\ Received: 20 February 2020; accepted: 13 June 2020
}

\begin{abstract}
Three formations were chosen in the present study, these are Yamamma, Zubair and Mishrif formations, which are considered the main reservoirs at Zubair oilfield southern Iraq, especially during the Cretaceous period. The studied reservoirs are distinguished by different rocks, facies and environmental specifications. Thirteen wells were selected for the present study these are: $Z b-44, Z b-202, Z b-10, Z b-294, Z b-81, Z b-233, Z b-329, Z b-49, Z b-9, Z b-156, Z b-8, Z b-256$ and $Z b-187$. To studying the geochemical parameters of crude oils. Geochemical analysis of crude oil was applied. The results of the isotope analyses indicate that the source rock of oil is a mature marine rock that contains a high percentage of sulfur. The American Petroleum Institute values are ranging from 35-20 indicate medium to light hydrocarbons. The results show that the Kerogen type is type II which is derived from marine algae organism. The burial history indicates that the subsidence is high at the late Jurassic - early Cretaceous period and also at the Miocene, and the slow subsidence during the late Cretaceous and moderate subsidence at the Paleogene. The results of the Vitrinite Reflection and Production Index show that the thermal maturity is happened at the early to the main stage, which was represented at the Zb-44 and Zb-202 wells. The transformation ratio of Zubair and Yamamma formations indicates that the possibility of kerogen to yield oil and gas is high in the future with temperature increasing.
\end{abstract}

Keywords: Geochemical isotopes; Burial history; Hydrocarbons maturation; Zubair Oilfield

\section{INTRODUCTION}

The source rocks have been widely adopted by several researchers as methods that can be applied successfully in geochemical analyzes, then to estimate and conclude the specifications of the evaluation of these hydrocarbons, such as determining amount of the organic matter with quality 
and level of maturity. The presence of a source rock considers the most important factor that governing in the nature of hydrocarbons. For the oil company's, it is essential to determine the best hydrocarbon zone and to estimate the hydrocarbon accumulations for exploration and development stages (Mohammed et al., 2020).

As Demaison and Huizinga (1991) stated, "If there are no rocks carry out of petroleum, all other necessary requirements lose their importance". In the current study, the Zubair field reservoirs were evaluated with other goals like rock potential, kerogen type, maturity, oil and gas transformation and transformation ratio $\left(T_{R}\right)$. Petroleum geochemistry represents important information to study the geochemistry of oil reservoirs and provides the necessary data for the reservoir and petroleum engineers. (Al-Ameri et al., 2001) explained that some oils of the Cretaceous formations like Yammama and Sulaiy source rocks in Basra, and considered it as potential source rocks. In both Basrah and Amara oilfields, the rocks mature as the result of increasing the sedimentary burial depth in Miocene (Alpine Orogeny effects) (Handhal et al., 2020). Jafar (2001) uses the models of thermal history in addition to the geochemical analysis to evaluate the Zubair Formation. He points out that the tectonic subsidence is more than the sedimentary subsidence towards the east and decreases towards the west and the Zubair Formation is within the stage of oil generation and expulsion which represents a source rock. Al-Shahwan (2002) carries out a study on the lower Cretaceous reservoirs, southern Iraq, and he recommends that the Yamama Formation is a good source rock situated in the mature zone of the oil window. The Yamama basin is indicated as a ramp setting in a stable flank of the carbonate platform. The ramp setting affects the stacking patterns of the Yamama Formation (Idan et al., 2020), while Zubair Formation is characterized by good organic matter richness at the early thermal stage of maturation. Zubair Formation is interpreted as three depositional sequences representing high stand systems tracts, which indicate to shelf margin platform due to sea level fall, this regarded promising reservoir (Ali and Kadhim, 2020). Al-Khafaji (2006) uses biomarkers and carbon isotopes in the correlation between the Mishrif crude oil and possible source rocks, Southern Iraq. He concludes that most of the crude oil accumulated in the Mishrif Formation, of Ratawi and Rumaila oil fields belongs to Jurassic source rocks such as Najmah and Sargelu formations, and the rest of the oil is from the Sulaiy Formation. Al-Mimar (2014) mentioned that the lower part of the Yamama Formation is considered as a mature source rocks and contributes in the hydrocarbon generation of cretaceous oils based on the kerogen extracts parameters and burial history of the Cretaceous reservoirs in Ad'Daimah oilfield. 
The main source rocks in the Iraqi oilfields is the Sarqelu Formation, the OM of Sargelu Formation was kerogen Types II and mixed II/III, that the kerogen thermally mature and frequently located within the oil generation zone (Al-Atroshi et al., 2020). The aims of the current study are studying the geochemical characterizations of the Yamama, Zubair and Mishrif crude oils, conducting the quantitative and qualitative organic geochemical assessment of prospective source rocks in an area interested and construct the burial history of the cretaceous successions and maturity stage of the source rocks.

\section{LOCATION OF THE STUDY AREA}

The Zubair oilfield is located in the southern part of Iraq, about $20 \mathrm{~km}$ west of the Basrah city, between longitude $\left(47^{\circ} 30^{\prime}-47^{\circ} 45^{\prime}\right)$ and latitude $\left(30^{\circ} 00^{\prime}-30^{\circ} 45^{\prime}\right)$. The length of the field is $70 \mathrm{~km}$ and the width $10 \mathrm{~km}$. The axis of Zubair field is parallel to the axis of the Rumaila field (NorthwestSoutheast), extending from the Iraqi-Kuwaiti border. The field is bounded to the north by the Nahr Umr field and to the west by the Rumaila field as shown in Fig.1. Thirteen selected oil wells are chosen for the study area, which is distributed at the Shauiba and Safwan domes (Table 1).

Table1. Sample numbers, depths and coordinates of the studied wells

\begin{tabular}{|l|c|c|c|c|c|}
\hline Wells & Formation & \multirow{2}{*}{ Depth } & \multicolumn{2}{|c|}{ Coordinate } & \multirow{2}{*}{ No. sample } \\
\cline { 4 - 5 } No. & & & X & Y & \\
\hline Zb-44 & Yamamma & 3780 & 765330 & 3333500 & 2 \\
\hline Zb-44 & Yamamma & 3810 & 765330 & 3333500 & 1 \\
\hline Zb-44 & Zubair 3pay & 3339 & 765330 & 3333500 & 1 \\
\hline Zb-202 & Yamamma & 4217 & 750495 & 3374320 & 1 \\
\hline Zb-10 & Zubair 4pay & 3519 & 753276 & 3358289 & 1 \\
\hline Zb-294 & Zubair 4pay & 3524 & 745758 & 3385145 & 1 \\
\hline Zb-81 & Zubair 3pay & 3358 & 747636 & 3387400 & 1 \\
\hline Zb-233 & Zubair 3pay & 3374 & 749919 & 3387400 & 1 \\
\hline Zb-329 & Zubair 3pay & 3318 & 747916 & 3359786 & 1 \\
\hline Zb-49 & Yamamma & 3775 & 743200 & 3387060 & 1 \\
\hline Zb-9 & Zubair 4pay & 3208 & 746019 & 3365933 & 1 \\
\hline Zb-156 & Mishrif & 2255 & 746019 & 3365933 & 2 \\
\hline Zb-8 & Yamamma & 3680 & 752937 & 3375745 & 1 \\
\hline Zb-8 & Zubair 4pay & 3040 & 752937 & 3375745 & 1 \\
\hline Zb-256 & Mishrif & 2275 & 752937 & 3375745 & 1 \\
\hline Zb-187 & Mishrif & 2281 & 750302 & 3381642 & 1 \\
\hline
\end{tabular}




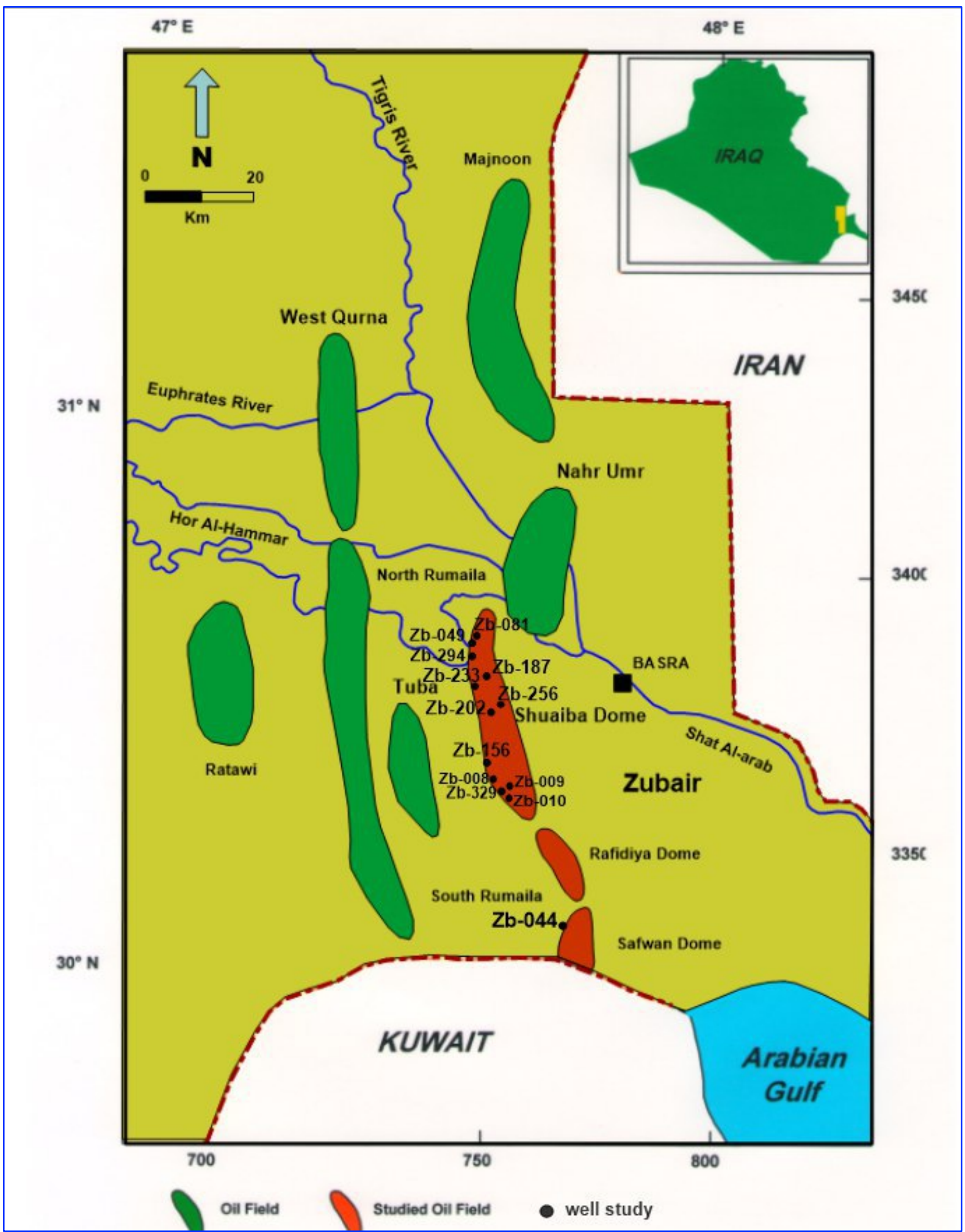

Fig. 1. Location map of the study area (OEC, 1987) 


\section{GEOLOGICAL SETTING}

The stratigraphy of the study area comprises of three formations, these are Yamamma, Zubair and Mishrif formations. Yamama formation was deposited in the Late Berriasian - Early Valangenian age (Bellen et al., 1959), within the Thumamah group. The lithology of the formation content of pure limestone sometimes peloidal limestone which deposited at coastal, shallow waters and deep inner shelf environments (Sadooni, 1993). The first appearance of the formation was started at the beginning of the benthonic foraminifera. The boundary between Yamama and Ratawi is conformable that appears at the beginning of pure limestone rocks that follow of the shale and clay that followed to Ratawi Formation. While defined the bottom of the formation at the appearance which followed to Sulaiy Formation at age Tithonian - Berriasian (Al-Siddiki, 1977). The thickness of the Yamama Formation in the Zubair field is approximately 400 meters (Jassim and Goff 2006). Zubair Formation was deposited at the Barremian - Aptian age, it located within the AP8 Megasequence (Sharland et al., 2001). The top of the Zubair Formation started at the beginning of the first layers of shale rocks over the carbonate rocks are followed to Shuaiba Formation. While the bottom of the formation at the beginning of the carbonate rocks which followed to Ratawi Formation. Contact boundary with Shuaiba and Ratawi formations is conformable (Owen and Nasr, 1958; Al-Naqib, 1967 and Ibrahim, 1983).

Mishrif Formation was deposited at the middle of Cretaceous, meaning that it belongs to the group of Al-Wasi, exactly at the late Cenomanian - Early Turonian cycle. The lower contact of the Mishrif Formation is conformable with the Rumaila Formation, while the upper contact is unconformable with the Khasib Formation (Aqrawi et al., 2010). The composition of the deposits of the Mishrif Formation consists of complex block of limestone which contains a mixed of planktonic and benthic fossils and rudists. The environment of formation is open to shallow outer shelf environment with organic building that formed in open lagoon to inner shelf environments. The thickness of the formation in southern Iraq ranges between 150-200 meters (Al-ayab et al., 1980) (Fig. 2).

Tectonically, the Zubair Field within the sagged basin at the quisplatiform of the Mesopotamia according to the tectonic divisions of Iraq (Numan, 1997), while it located at the stable shelf in the Mesopotamian zone (Jassim and Goff, 2006) (Fig. 3). The Zubair field is a longitudinal, symmetrical, convex, uneven and non-cylindrical convex fold (Turner and Weiss, 1963). 


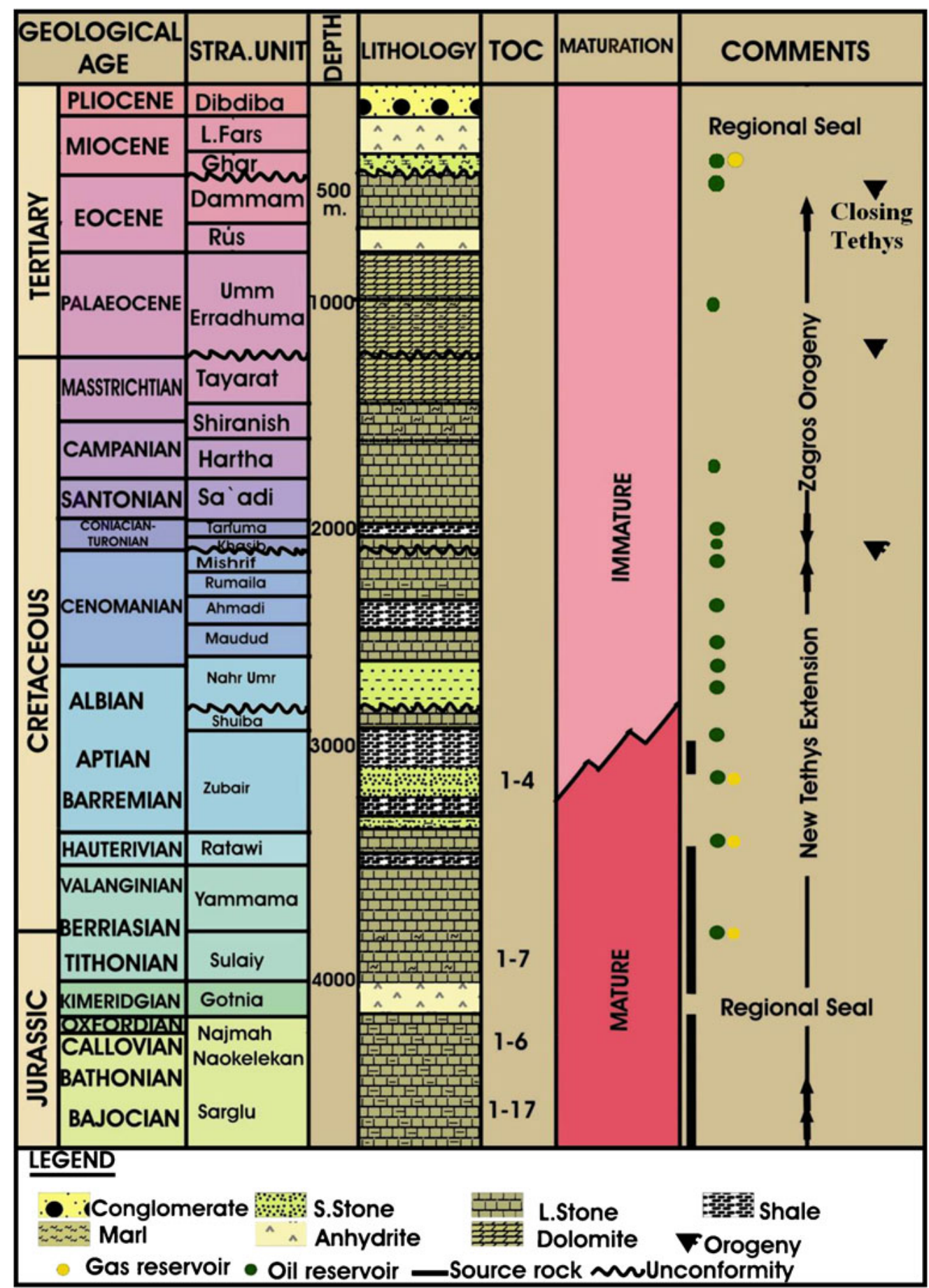

Fig. 2. The stratigraphic column to the studied area (Al-Ameri et al, 2011) 


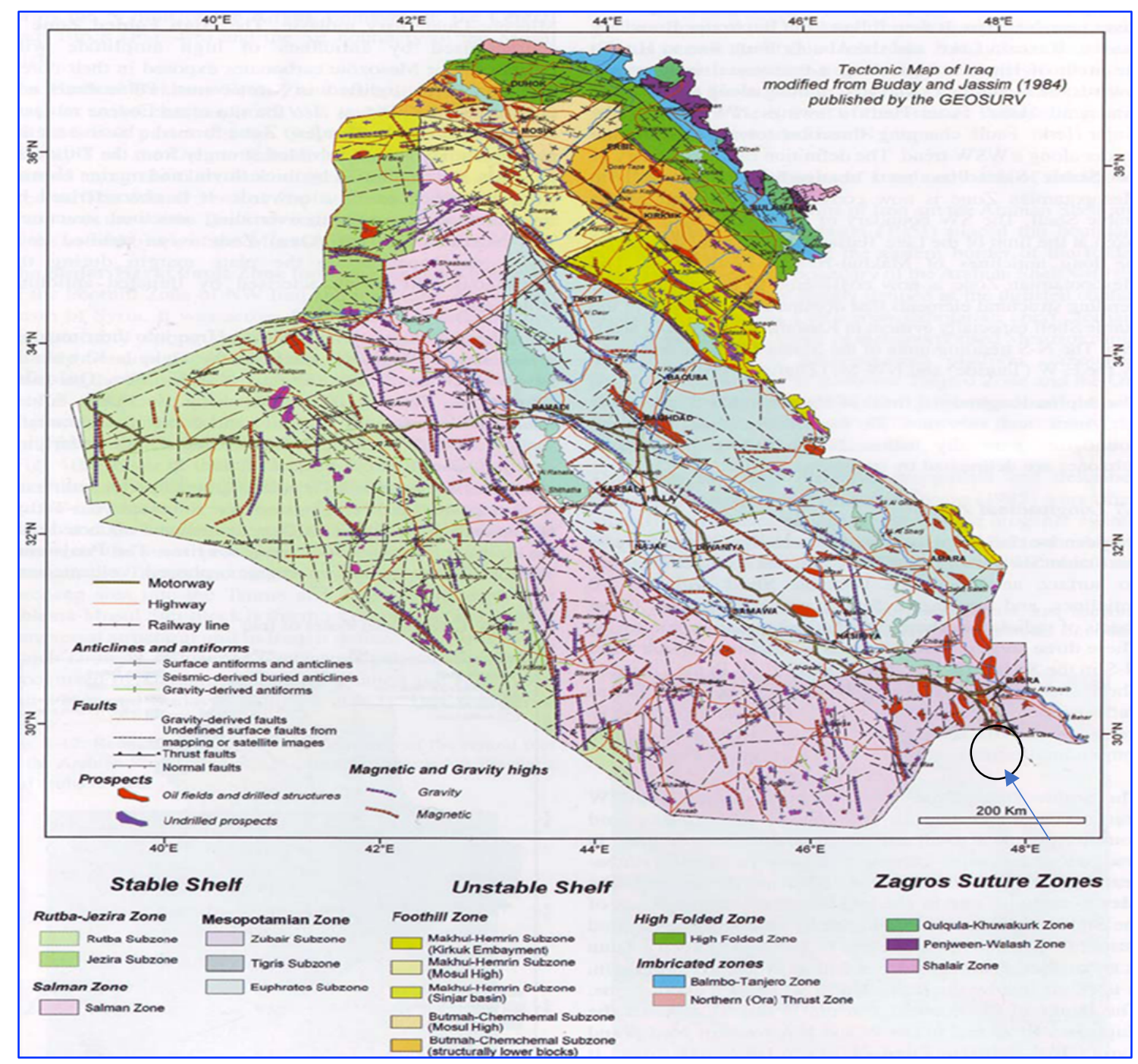

Fig. 3. The tectonic division of Iraq (Jassim and Goff, 2006)

\section{MATERIALS AND METHODS}

Many methods are used in the present study as follow:

1. High Performance Liquid Chromatography (HPLC)

The crude oil samples were analyzed after isolating the asphalt by injecting an amount of the oil into the separation column directly with amount not exceeding $2 \mathrm{cc}$. The flow rates of the device are up to $20 \mathrm{ml}$ per minute and the total time to separate the compounds is within 25 minutes. The type of the detector used in this technique is the Reflection Index (RI), which enters into another detector which called UV. By using the special software is called Clarity that followed to with this device, that technique could calculate of the concentrations of Saturates compounds and Aromatics and Resins. 
2. By using the sulfur measuring device in oil, the sulfur content (Sulfur Analysis) has been calculated.

3. Specific gravity was calculated from equation followed:

$$
A P I=\left(\frac{141.5}{S G}-131.5\right)
$$

Where a specific gravity (SG) weight at $60^{\circ} \mathrm{F}$. This equation was used for calculation and classification of the specific density of oil by depending on API.

4. Saturates- Aromatic- Resins-Asphaltenes (S-A-R-A) Technique

A small rock sample of 80-100 mg was taken from source rocks based on their degree of oil saturation. The results of this technique are shown below as hydrocarbonic sections:

$\mathrm{S}_{1}$ : it represents the amount of free hydrocarbon released at low temperatures up to $100{ }^{\circ} \mathrm{C}$.

$\mathrm{S}_{2}$ : it represents the amount of free hydrocarbon released at high temperatures of $600{ }^{\circ} \mathrm{C}$.

$\mathrm{T}_{\max }$ : it is the highest temperature that can generate the maximum amount of hydrocarbon which represents the peak of $S_{2}$ curve.

5. PETROMOD 1D software

PetroMod petroleum systems modeling software is a finite - element basin to describe thermal and burial history, source rock maturation, and petroleum generation. The requirement of studied wells to construct the burial history are provided from well logs, final geological reports, lithological studies and geochemical analyses.

\section{RESULTS}

Depending on the analyses of samples, there are important results were calculated:

\section{Laboratory Tests}

Laboratory tests were conducted for crude oil samples and the results are illustrated in Table 2.

\section{Liquid Chromatography Tests}

The results of the hydrocarbon groups are shown in Table 3.

\section{Stable Carbon Isotope $\left(\delta^{13} \mathrm{C} \%\right)$}

The stable carbon isotope is used to correlate of petroleum, kerogen and bitumen and to determine the source rocks of oil, age, and depositional environments. It can be calculated using the following equation of Sofer, 1984:

$$
C_{v}=-2.53^{13} \delta C_{\text {sat }}+2.22^{13} \delta C_{\text {aro }}-11.65
$$

The results show the CV (Canonical variable) values ranged between -4.09 and -2.10 (Table 3). 
Table 2. Characteristics of the crude oil in the Zubair oilfield

\begin{tabular}{|c|c|c|c|}
\hline Wells No. & Formation & ApI $^{\circ}$ & S \% \\
\hline Zb-202 & Yamama & 35.0 & 2.3 \\
\hline Zb-10 & Zubair4pay & 34.0 & 2.5 \\
\hline Zb-81 & Zubair3pay & 20.0 & 4.0 \\
\hline Zb-233 & Zubair3pay & 28.0 & 4.5 \\
\hline Zb-329 & Zubair3pay & 31.0 & 3.2 \\
\hline Zb-156 & Mishrif & 27.0 & 4.3 \\
\hline Zb-256 & Mishrif & 26.7 & 4.4 \\
\hline Zb-187 & Mishrif & 25.5 & 4.3 \\
\hline
\end{tabular}

Table 3. Geochemical parameters of crude oils of the studied samples

\begin{tabular}{|c|c|c|c|c|c|c|c|c|c|}
\hline \multirow{2}{*}{$\begin{array}{c}\text { Nells } \\
\text { No. }\end{array}$} & \multirow{2}{*}{ Depth } & Formation & \multicolumn{3}{|c|}{ Liquid Chromatography Wt\% } & \multicolumn{2}{c|}{ Stable Carbon Isotopes } \\
\cline { 4 - 10 } & & & Sat. & Arom. & Resins & Asphalt & Sat \%o & Arom \%o & CV \\
\hline Zb-202 & 4217 & Yamama & 30.21 & 43.11 & 13.6 & 10.2 & -27.21 & -26.71 & -2.10 \\
\hline Zb-10 & 3519 & Zubair4pay & 30.70 & 41.10 & 13.5 & 11.7 & -27.03 & -27.40 & -4.09 \\
\hline Zb-81 & 3358 & Zubair3pay & 31.77 & 44.52 & 13.1 & 8.4 & NA & NA & NA \\
\hline Zb-233 & 3374 & Zubair3pay & 29.40 & 46.55 & 12.5 & 8.7 & -27.06 & -26.79 & -2.66 \\
\hline Zb-329 & 3318 & Zubair3pay & 33.03 & 45.64 & 12.6 & 8.6 & -27.27 & -27.61 & -3.95 \\
\hline Zb-156 & 2255 & Mishrif & 36.30 & 44.70 & 13.1 & 5.7 & NA & NA & NA \\
\hline Zb-256 & 2275 & Mishrif & 25.9 & 54.50 & 13.8 & 5.4 & NA & NA & NA \\
\hline Zb-187 & 2281 & Mishrif & 26.6 & 53.90 & 11.15 & 7.8 & -27.30 & -27.51 & -3.65 \\
\hline
\end{tabular}

4. By using the geochemical parameters, TOC values and thermal pyrolysis analyses of rock samples, we can determine the type of kerogen, the maturity and generation of hydrocarbons (Table 4). 
Table 4. The results of SARA analysis for studied samples at the Zubair oilfield

\begin{tabular}{|l|c|c|c|c|c|c|c|c|c|}
\hline Wells No. & Depth & Formation & $\begin{array}{c}\text { S1 mg HC/g } \\
\text { Rock }\end{array}$ & $\begin{array}{c}\text { S2 mg HC/g } \\
\text { Rock }\end{array}$ & Tmax ${ }^{\circ} \mathrm{TOC}$ & P. I & H. I & Ro \\
\hline Zb-44 & 3780 & Yamama & 3.71 & 8.70 & 434 & 1.75 & 0.29 & 497 & 0.65 \\
\hline Zb-44 & 3810 & Yamama & 4.10 & 7.05 & 434.1 & 1.50 & 0.36 & 470 & 0.65 \\
\hline Zb-294 & 3524 & Zubair4pay & 2.53 & 4.44 & 432.4 & 1.13 & 0.36 & 398 & 0.62 \\
\hline Zb-44 & 3339 & Zubair3pay & 1.80 & 6.27 & 431.5 & 1.71 & 0.22 & 366 & 0.60 \\
\hline Zb-8 & 3680 & Yamama & 3.10 & 6.76 & 435 & 1.75 & 0.31 & 386 & 0.67 \\
\hline Zb-8 & 3040 & Zubair4pay & 1.19 & 3.44 & 434.8 & 0.82 & 0.25 & 419 & 0.66 \\
\hline Zb-49 & 3775 & Yamama & 2.52 & 5.58 & 431.6 & 1.40 & 0.31 & 398 & 0.60 \\
\hline Zb-9 & 3208 & Zubair4pay & 1.09 & 1.95 & 433 & 0.41 & 0.35 & 475 & 0.63 \\
\hline
\end{tabular}

\section{DISCUSSION}

The geochemical analyses of crude oil indicated that the Yamamma Formation contains light oil, while the Zubair Formation, 4 pay contains medium to light oil and the 3 pay contains medium to heavy oil, whereas the Mishrif Formation contains only medium oil. Thus, it can be concluded that the crude oil of Yamamma Formation is the most mature compared to crude oil of the Zubair and Mishrif formations (Fig. 4 and Fig. 5). The oil contains a high percent of sulfur which indicates it is deposited in marine environment at anoxic conditions (Fig. 4). The maximum value of the sulphur content was in the Mishrif Formation while the lowest was in the Yamama Formation. Aromatic compounds are the major components in the studied samples of crude oils followed by the saturated compounds which indicated non -degraded mature oils generated under anoxic conditions (Fig. 6). The medium value of asphalt and waxes in all formations are supported by high ratio of aromatic compounds, but the oil stills classified as non -waxy oils.

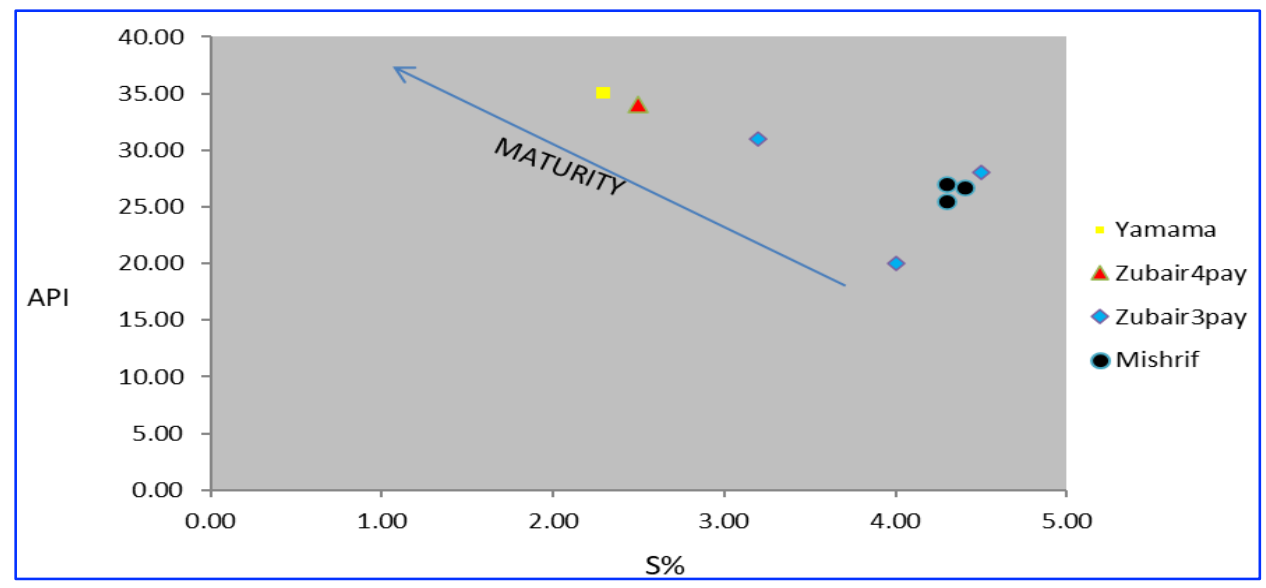

Fig. 4. The relationship between $A P I^{\circ}$ gravity and sulfur content of the studied crude oil samples 


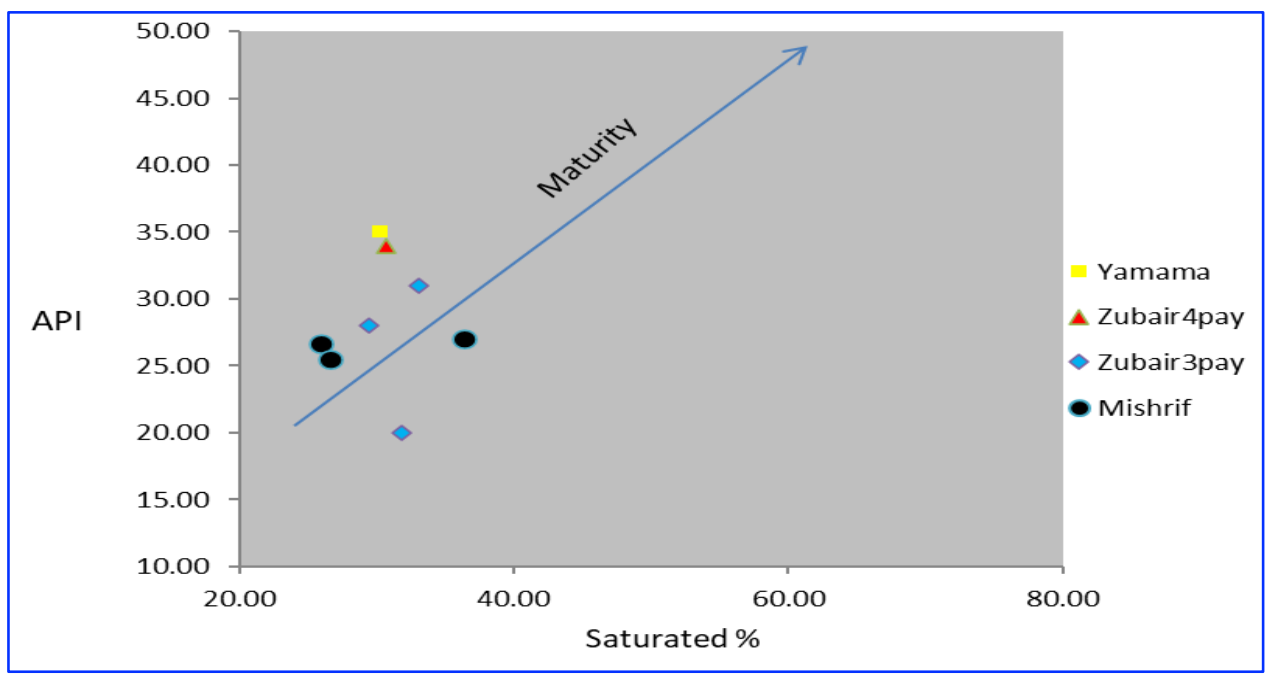

Fig. 5. The relationship between $\mathrm{API}^{\circ}$ gravity and saturated compounds

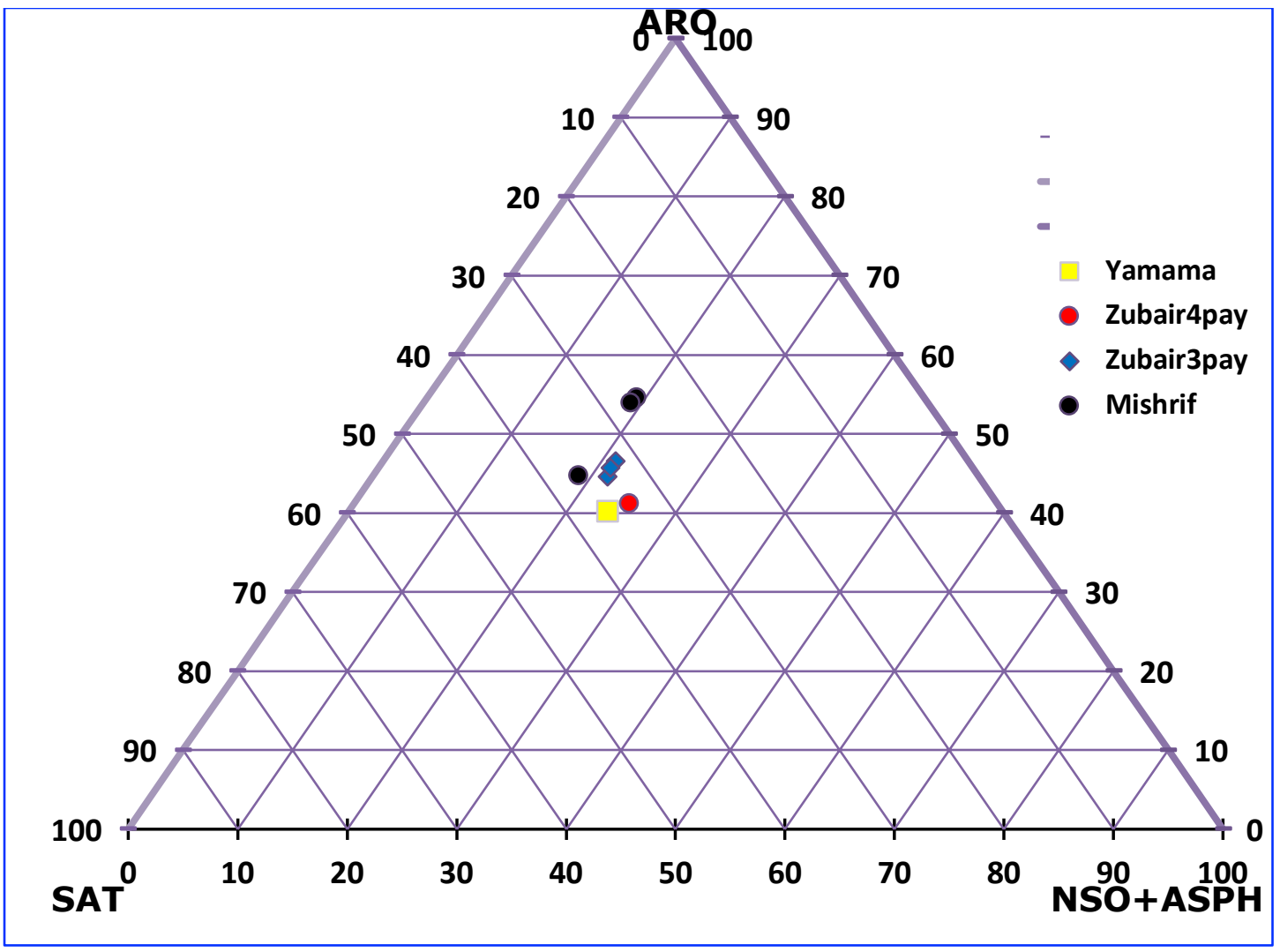

Fig. 6. Triangular diagram of the chemical composition of crude oil samples

The values of CV showed that the all crude oil samples in the study area are less than 0.47 and the $\delta 13$ of $\delta^{13} \mathrm{C}_{\text {sat }}$ and $\delta^{13} \mathrm{C}_{\text {aromatic }}$ indicated that crude oil are deposited in marine environment (Fig. 7). 


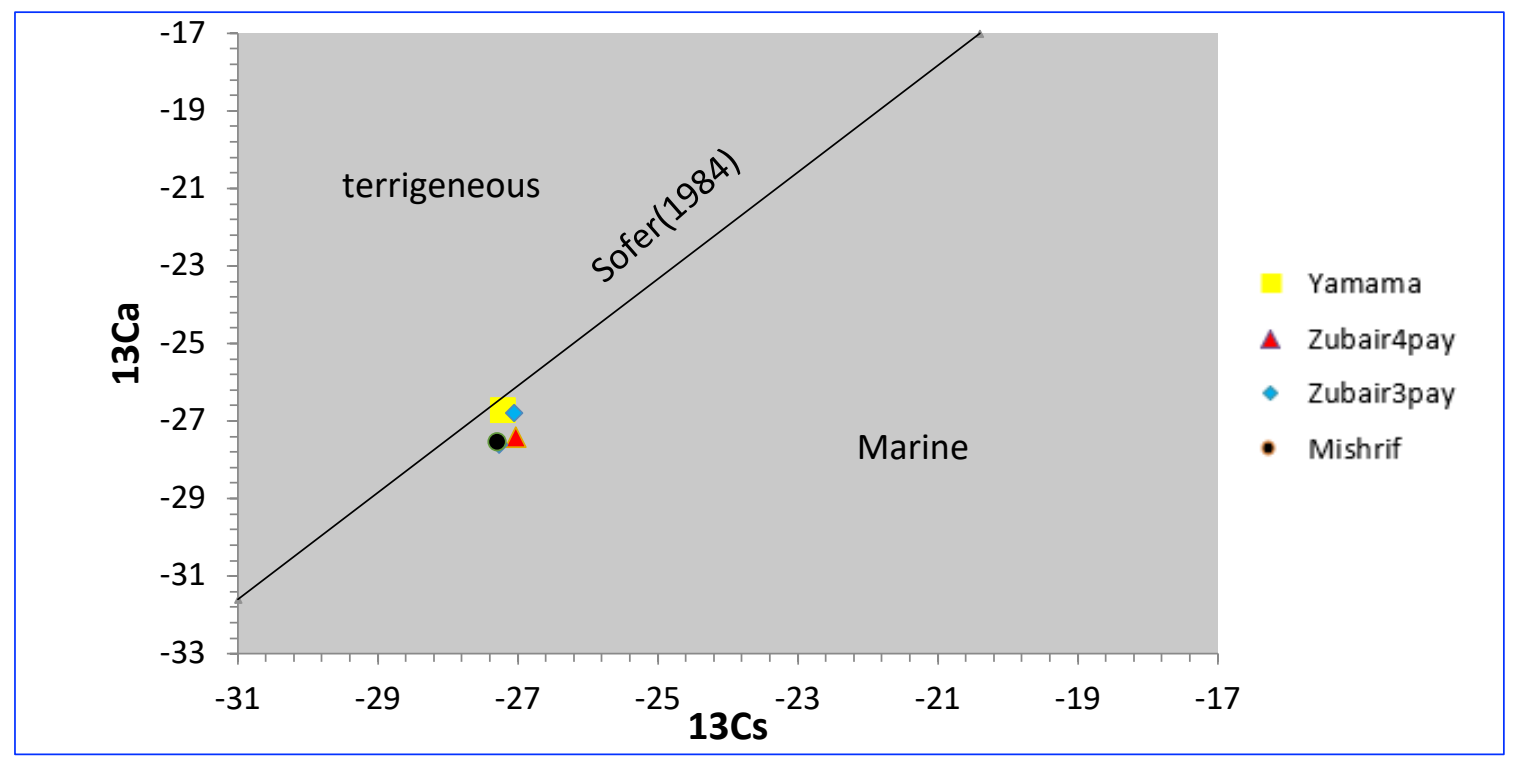

Fig. 7. The relationship between $\delta^{13} C_{\text {aromatic }}$ and $\delta^{13} C_{\text {saturates }}$ for crude oil samples

Total organic carbon ranges between 0.41 and $1.75 \mathrm{wt} \%$ which indicated that the quality of TOC is poor to good. The thermal pyrolysis values showed that $\mathrm{S}_{1}$ ranging between 0.88 and 4.10, while $S_{2}$ ranging between 1.53 and 8.70 which indicate the potential is poor to excellent in the selected oil wells of the study area. According to Peter and Cassa ,1994, the Yamama Formation shows a good ratio of TOC (1.5-175\%) indicates good potential source rocks while TOC in the Zubair Formation ranges from $0.4-1.75 \%$ indicates poor to good potential source rocks (Table 5). The relationship between $\mathrm{S}_{2}$ and TOC showed that the type of kerogen is type II and the source of the crude oil is deposited at marine environment (Algal and Herbaceous) (Fig. 8).

Table 5. The Equivalent TOC wt\% to extracted organic matters (Peters and Cassa, 1994)

\begin{tabular}{|l|c|c|c|c|}
\hline $\begin{array}{c}\text { Petroleum } \\
\text { Potential }\end{array}$ & $\begin{array}{c}\text { Bitumen } \\
\mathbf{( w t \% )}\end{array}$ & $\begin{array}{c}\text { Bitumen } \\
\mathbf{( p p m )}\end{array}$ & $\begin{array}{c}\text { Hydrocarbon } \\
\mathbf{( p p m )}\end{array}$ & $\begin{array}{c}\text { Equivalent TOC } \\
\mathbf{( w t \% )}\end{array}$ \\
\hline Poor & $<0.05$ & $<500$ & $<300$ & $<0.5$ \\
\hline Fair & $0.05-0.10$ & $500-1000$ & $300-600$ & $0.5-1.0$ \\
\hline Good & $0.10-0.20$ & $1000-2000$ & $600-1200$ & $1.0-2.0$ \\
\hline VeryGood & $0.20-0.40$ & $2000-4000$ & $1200-2400$ & $2.0-4.0$ \\
\hline Excellent & $>0.40$ & $>4000$ & $>2400$ & $>4.0$ \\
\hline
\end{tabular}




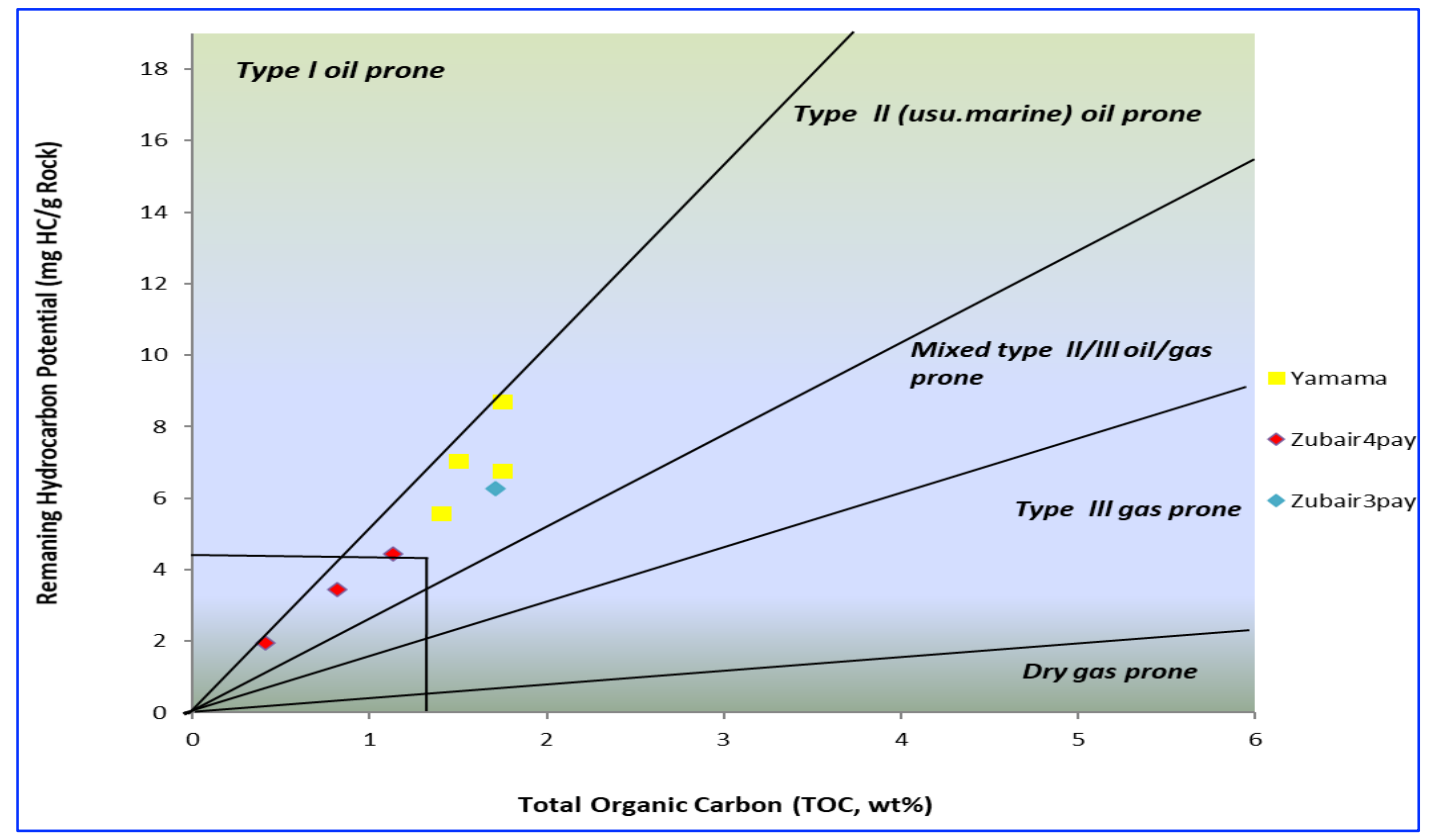

Fig. 8. Kerogen type of the rock samples

There are different settlement periods, ranging from high settlement at the upper Jurassic - lower Cretaceous, in addition to Miocene period, and slow settlement at the upper Cretaceous with moderate settlement at the Paleogene. The Yamamma Formation is recorded the highest temperature compared with the other formations, due to its great depth therefore the Yamamma Formation is considered the most matured formation as compared with the other formations. The thermal conductivity at studied formations in the Zubair oilfield revealed that the high percent of conductivity focused at the Umm Er- Radhuma and Rus formations, while the low conductivity located at Zubair and Tanuma formations (Fig. 9 and Fig. 12). Vitrinite reflectance in both of the Zubair and Yamama formations are more than $0.5 \%$ and less than $1 \%$ and the production index (PI) ranges from 0.22 to 0.36 indicate that the thermal maturity is at the early mature stage (oil window), except of the Yamamma Formation at well Zb-202 represent the main oil stage (Fig.1315). The maximum transformation ratio $\left(T_{R}\right)$ is observed in the Yamamma Formation at the $Z b-44$ well. There is a possibility that kerogen will be converted into oil and gas with a cumulative in proportion in the future by increasing of burial and temperature (Table 6). The high percent of generation for oil and gas has been recorded in the Zubair Formation at well Zb-44 (Fig. 16). 


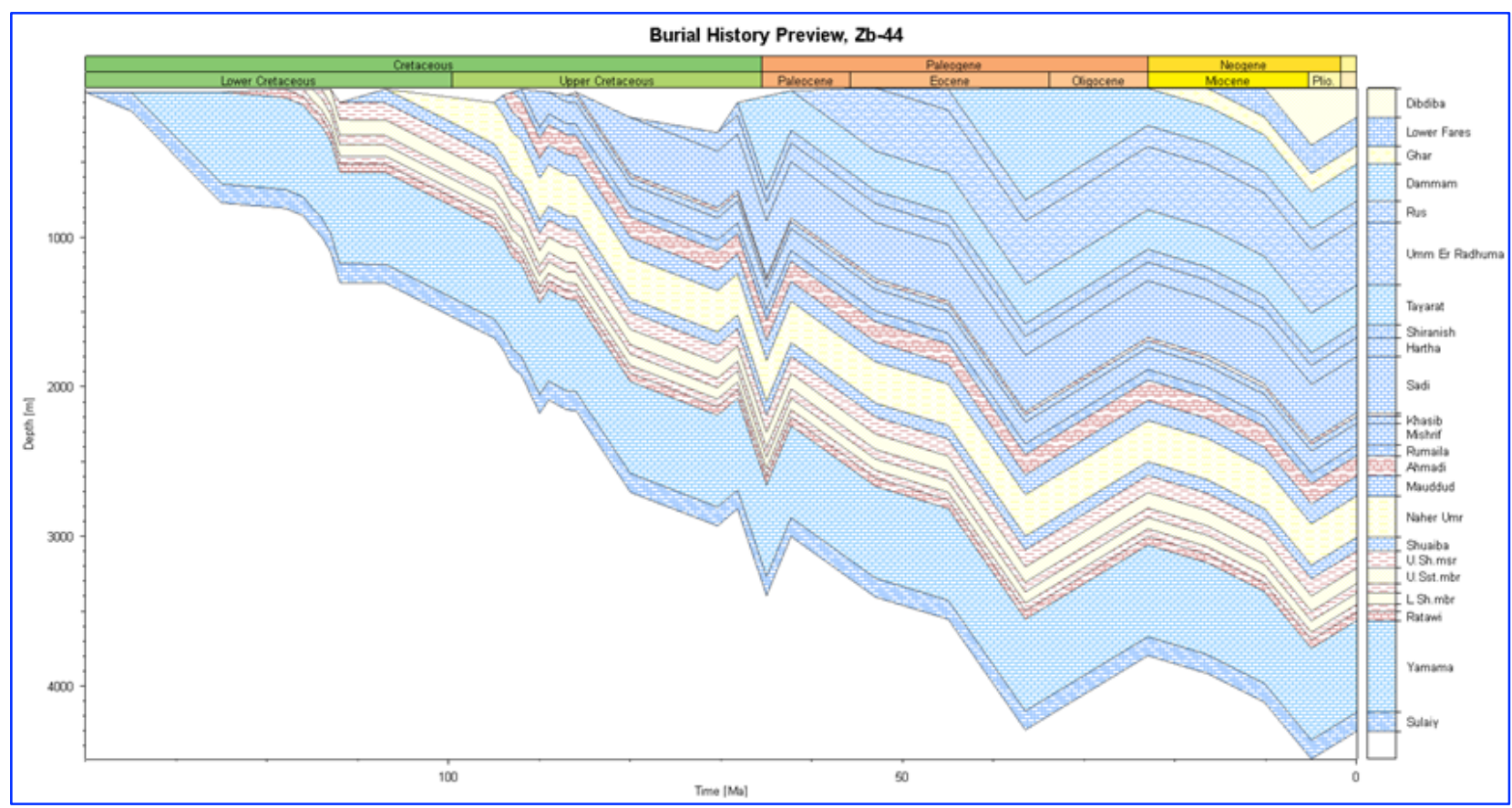

Fig .9. The burial history of the $\mathrm{Zb}-44$ well

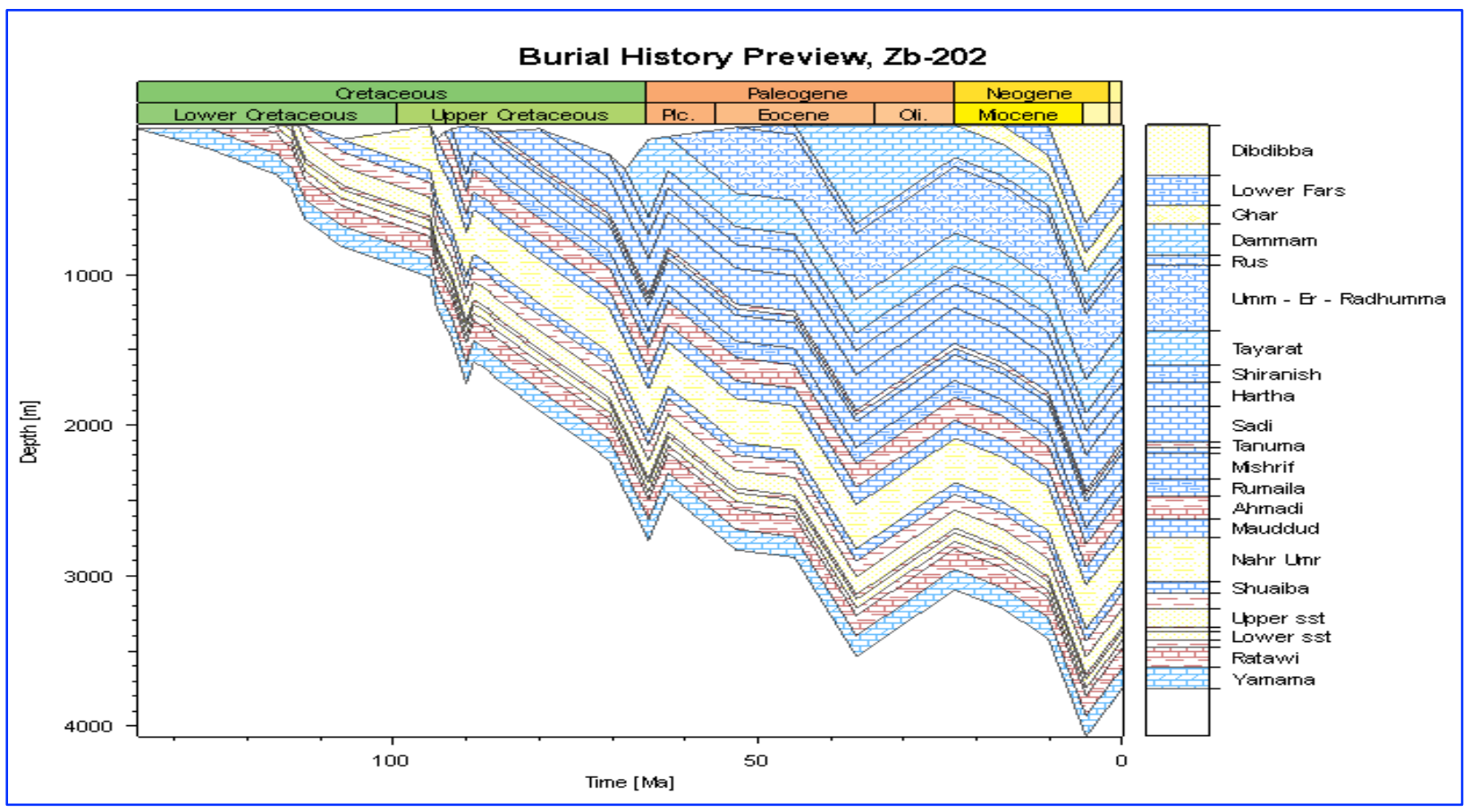

Fig. 10. The burial history of the Z-202 well 


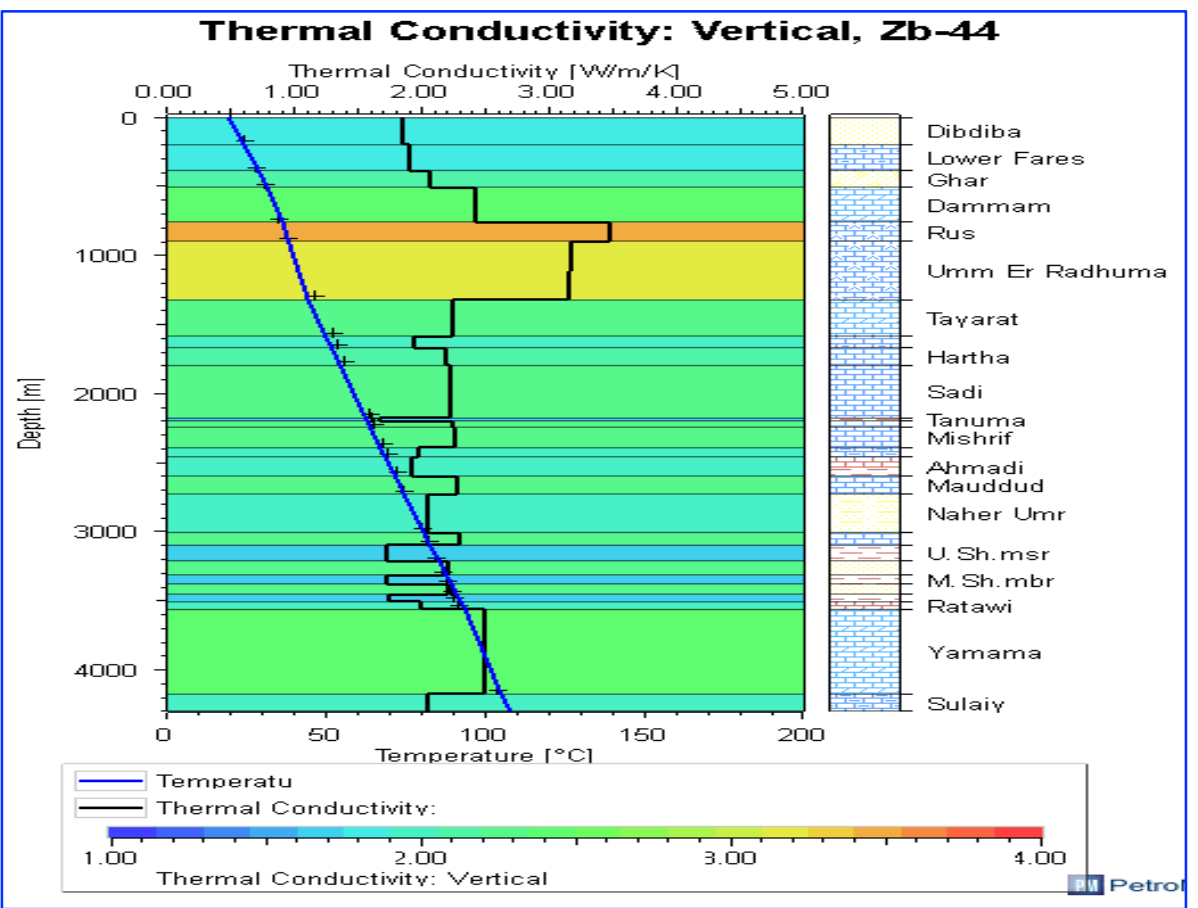

Fig. 11. Temperature and thermal conductivity of $\mathrm{Zb}-44$ well

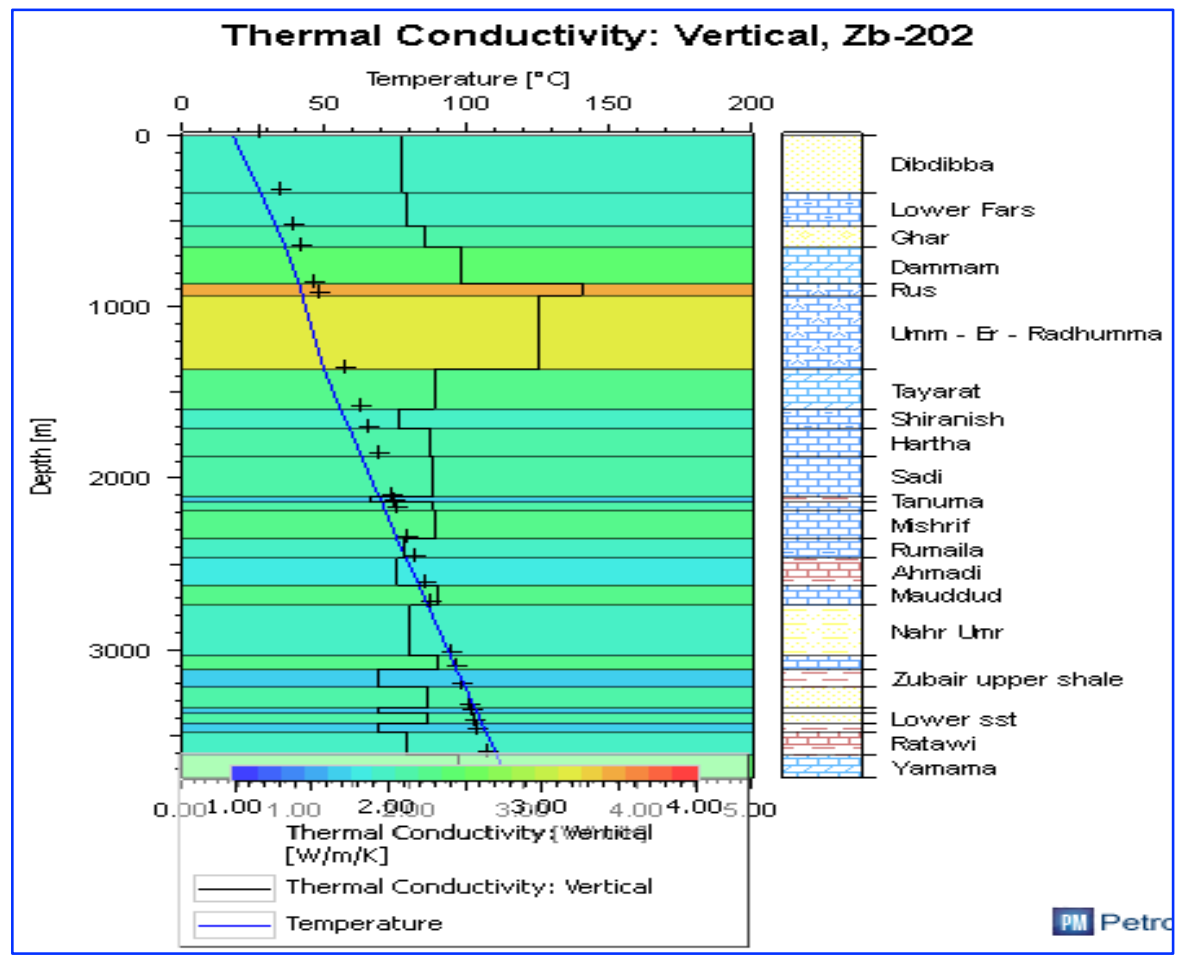

Fig. 12. Temperature and thermal conductivity of $\mathbf{Z b - 2 0 2}$ well 


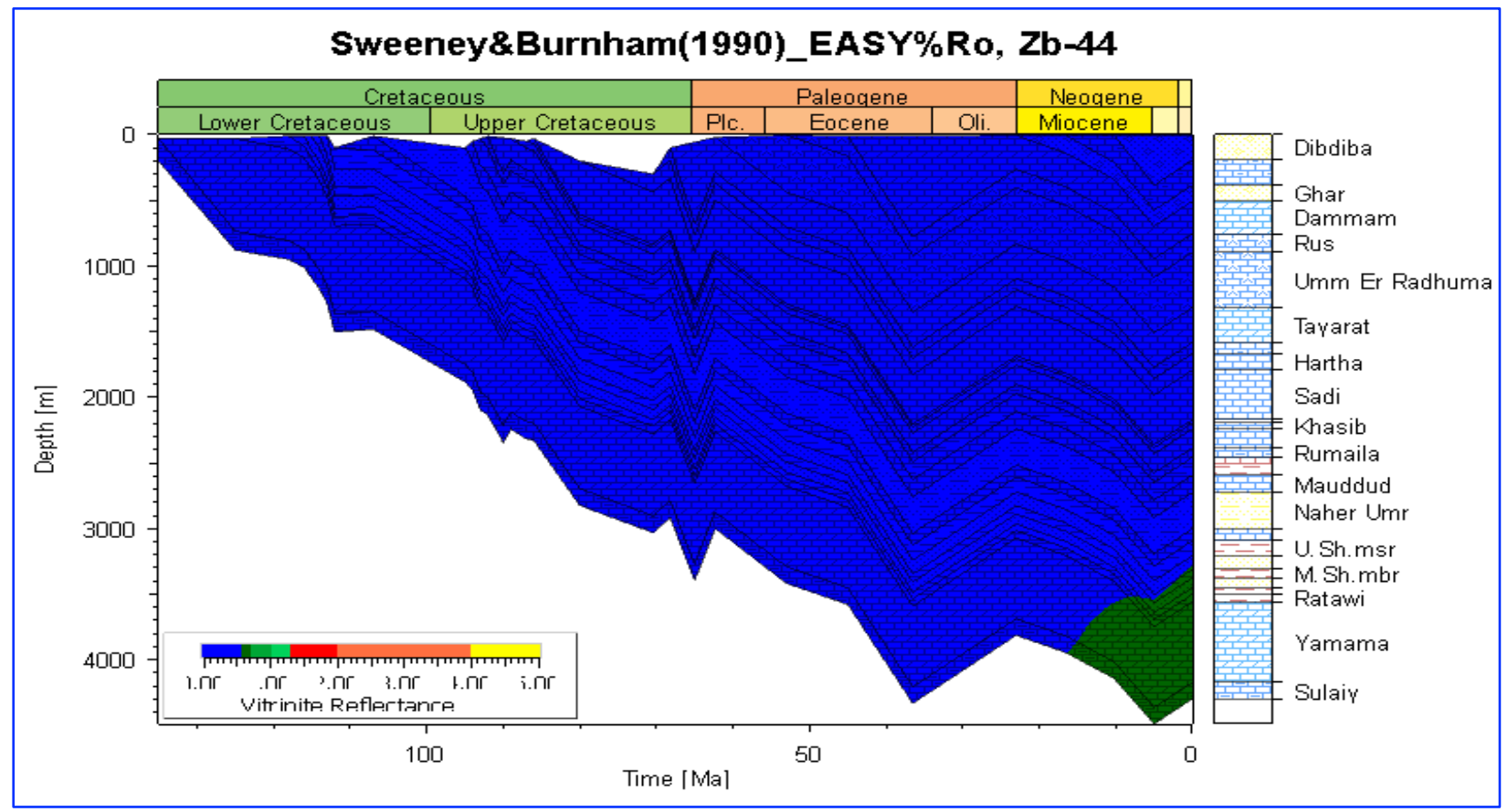

Fig. 13. Vitrinite reflection and burial history of the $\mathrm{Zb}-44$ well

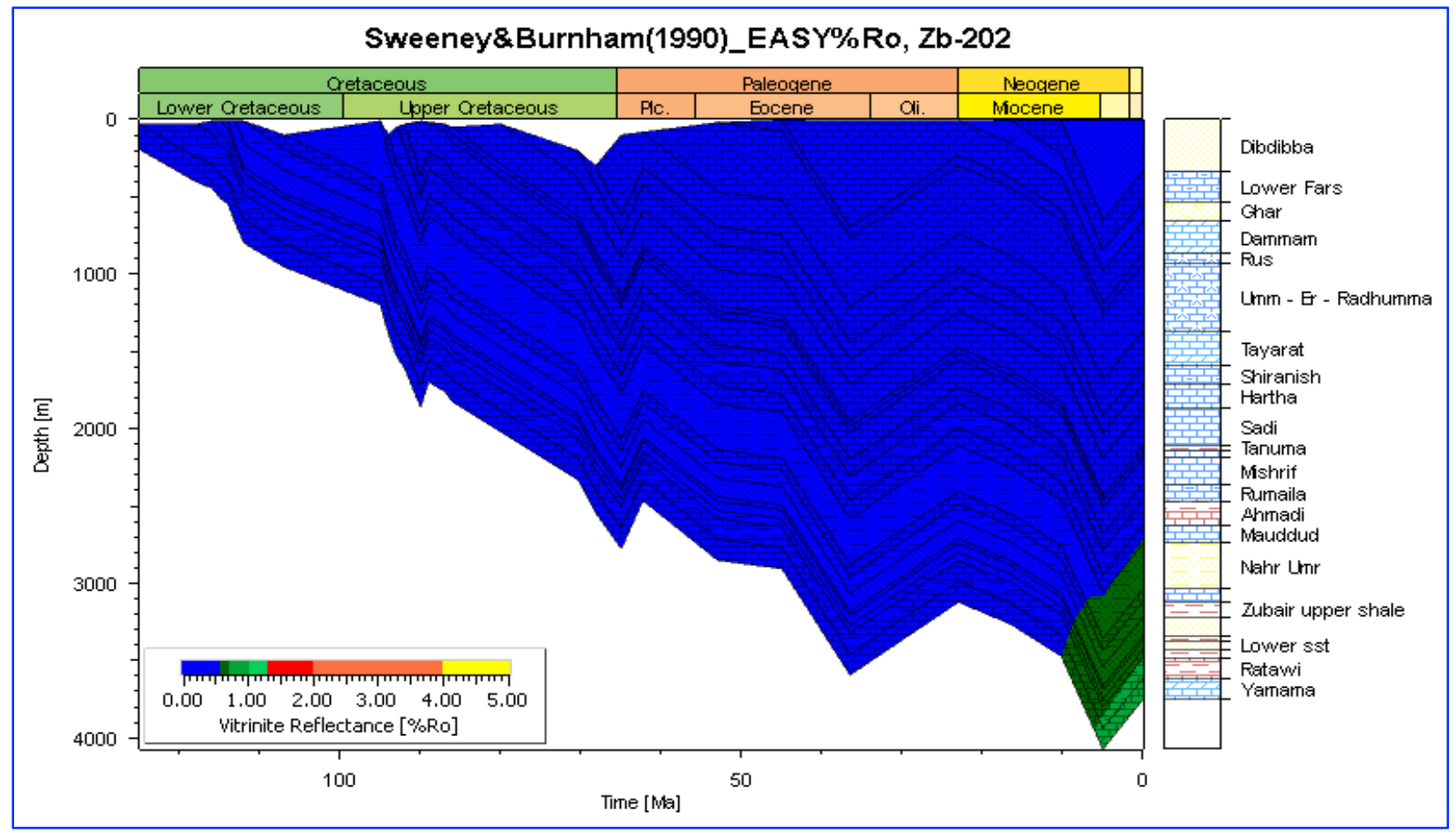

Fig. 14. Vitrinite reflection and burial history of the $\mathrm{Zb}-202$ well 


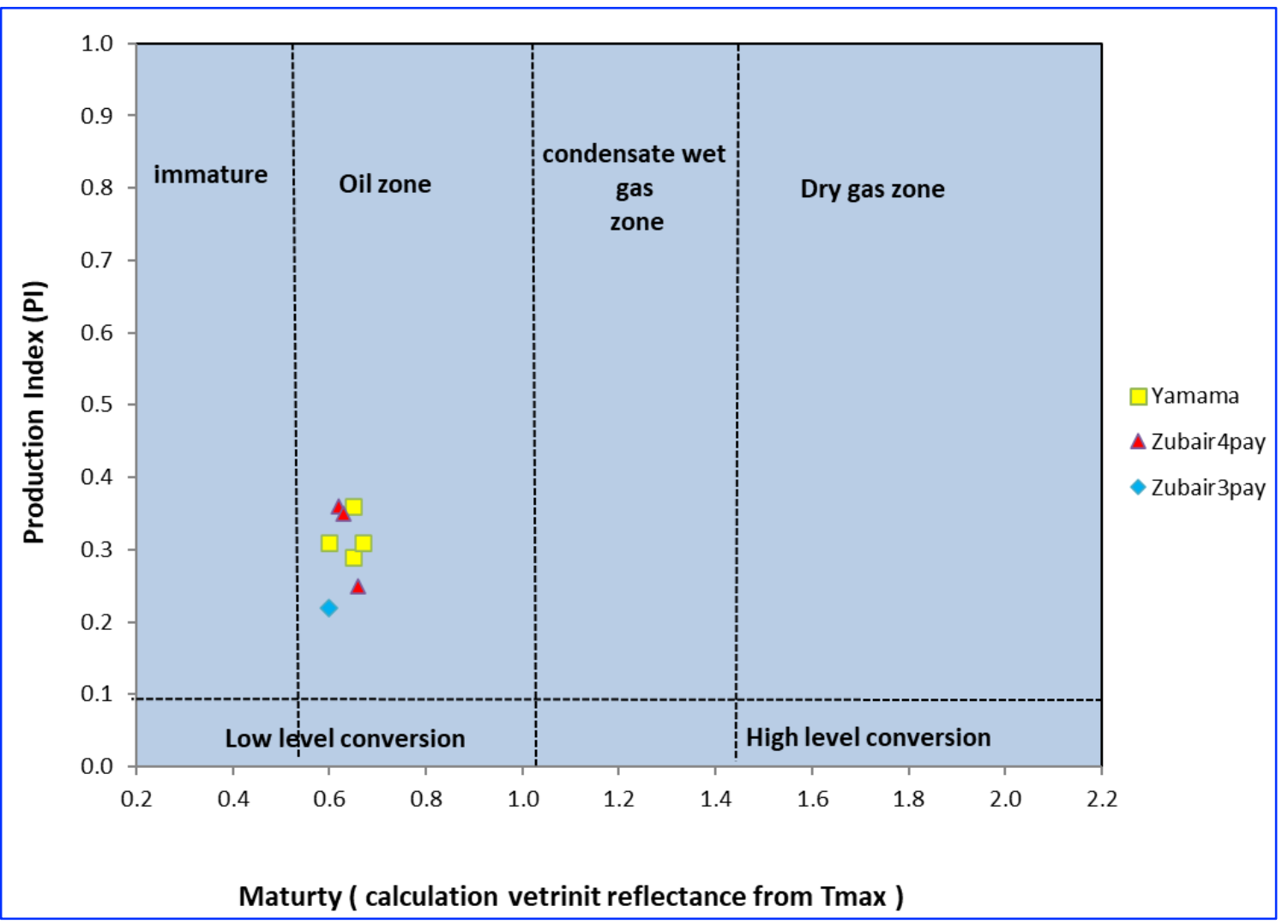

Fig. 15. Mature of the production index (PI) relations depending on the vitrinite reflectance

Table 6. Transformation rate $\left(T_{R}\right)$ of $Z b-44$ well

\begin{tabular}{|l|c|c|c|c|}
\hline \multirow{2}{*}{ Formation } & \multicolumn{2}{|c|}{ Start } & \multicolumn{2}{c|}{ End } \\
\cline { 2 - 5 } & TR \% & Time (Ma) & TR\% & Time (Ma) \\
\hline Yamama & 0.01 & 3.13 & 1.54 & 0 \\
\cline { 2 - 5 } & 0.01 & 3.04 & 0.65 & 0 \\
\hline Zubair & Very few & 1.56 & 0.18 & 0 \\
\cline { 2 - 5 } & Very few & 1.63 & 0.14 & 0 \\
\hline
\end{tabular}




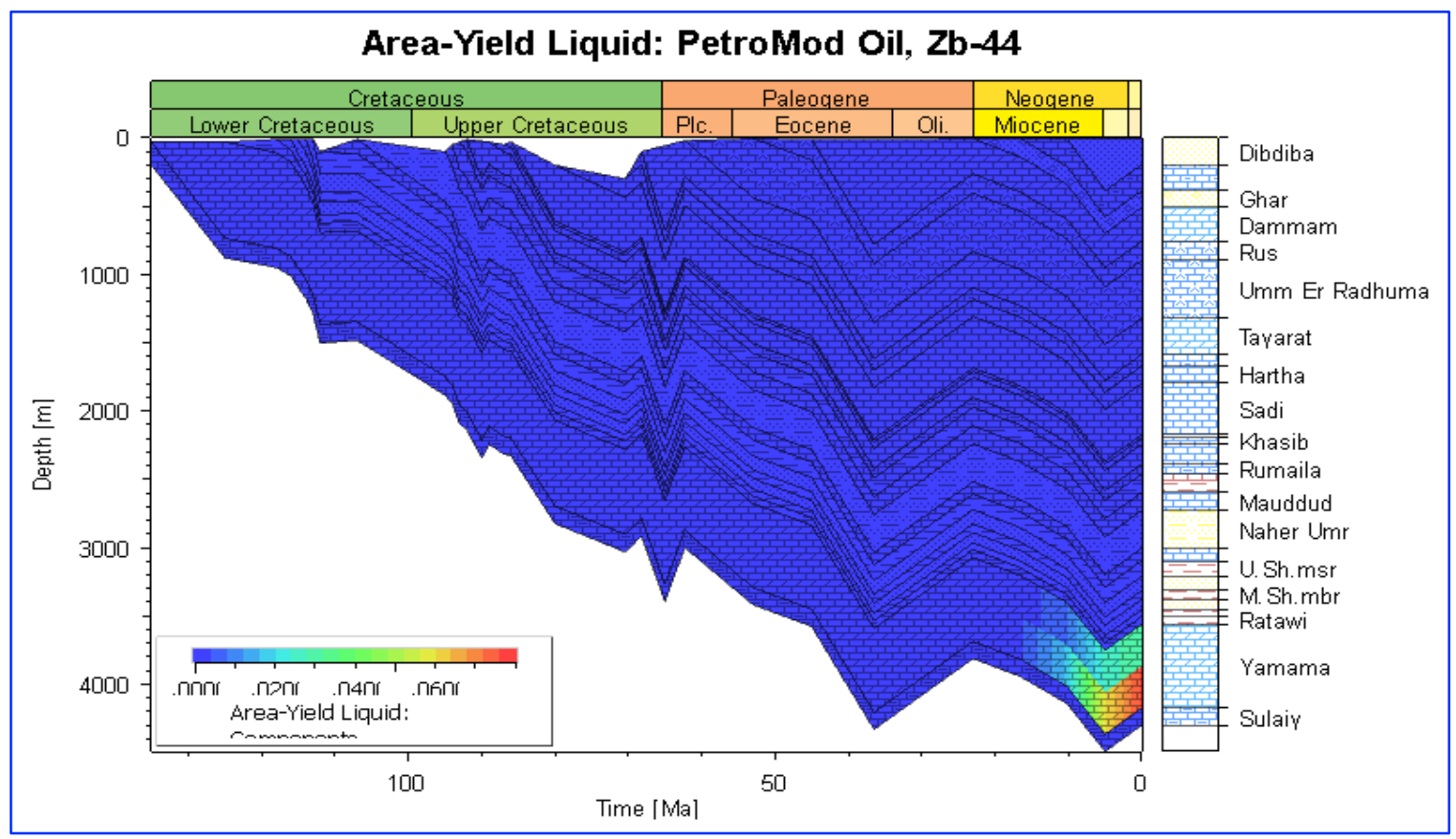

Fig. 16. Oil and gas generation of $\mathrm{Zb}-44$ well

\section{CONCLUSIONS}

1. According to the bulk geochemical characterizations of crude oils, Yamama, Zubair and Mishrif formations can be classified as a one family represents an early - oil window mature stage, the ratios of waxes, asphalts and sulphur content represent non - waxy oils deposited under marine anoxic environments

2. The kerogen types of the studied formations are mostly type II (algal marine).

3. According to the organic assessment of the Yamama and Zubair formations, the Yamama is considered as a mature source rock at the early mature stage with good TOC content while the Zubair Formation shows fair- good productivity of hydrocarbons, some samples are matured while others are not.

4. The Yamama and Zubair formations are contributes in generation of the cretaceous reservoir's hydrocarbons in addition to the upper Jurassic source rocks (Sargelu Formation) that have been proven by the previous studies.

5. Depending on $\mathrm{API}^{\circ}$ gravity classification, the crude oil of the Yamama Formation is light, Zubair crude oils from light- heavy while the Mishrif crude oils are medium. The Yamama crude oil is the most mature as compared with the Zubair and Mishrif crude oils. 


\section{ACKNOWLEDGMENTS}

The authors are very grateful to the Editor in Chief Prof. Dr. Salih M. Awadh, the Secretary of Journal Mr. Samir R. Hijab and the Technical Editor Dr. Heba S. Al-Mimar for their great efforts and valuable comments.

\section{REFERENCES}

$\mathrm{Al}$ - Ameri and Jafar, M. S., 2011. Hydrocarbon generation modeling of the Basrah oilfield, southern Iraq. Arabian Journal of Geoscience, 4:1239-1259 DOI 10.1007/s12517-010-0160-z.

Al-Ameri, T. K., Al - Najar, T. K., and Batten, D. J., 2001. Palynostratigraphy of depositional environment and source potential for hydrocarbons, the mid Cretaceous Nahr Umr, lower Mauddud formations, southern Iraq. Cretaceous Research, 22: 735 -742.

Al-Atroshi, S. J., Sherwani, J. H. and Al-Naqshbandi, S. F., 2020. Assessment the hydrocarbon potentiality of the middle Jurassic Sargelu Formation, Northern Iraq, Iraqi Geological Journal. 53 (1A):1-15.

Al-Khafaji, A. S., 2006. Relation of Mishrif Reservoir Crude oil with the Mishrif Formation and Source rocks, using Biomarkers and Carbon Isotopes, Ratawi, South and north Rumaila oil fields, southern Iraq. (in Arabic), Unp. Msc. Thesis. Univ. of Baghdad, 188P.

Al-Mimar, H. S., 2014. Petroleum System Analysis and Reservoir Development of Ad'Daimah oilfield, Messan Governorate, South of Iraq, M. Sc thesis, Baghdad University, 115 P.

Al-Naqib, K. M., 1967. Geology of the Arabian Peninsula. South- Western Iraq, U.S Geol. Survey. Prof. Paper 560G. (Washington), 54p.

Al-Sayab, A., 1989. Geology of Petroleum, 472 pp. University of Baghdad press, Baghdad.

Al-Shahwan, M. F., 2002. Thermal Maturity Patterns of the Lower Cretaceous, Southern Iraq: Implication of Hydrocarbon Potential. Unp. Ph. D. Thesis, college of science, Baghdad university, 196 P.

Al-Siddiki, A. A. M., 1977. Subsurface geology of south eastern Iraq: 10h Arab Petroleum Congress, 141:47p.

Ali, K. K., and Kadhim, G. F., 2020. 3d Seismic attributes interpretation of Zubair Formation in Al-Akhaideir area, Southwestern Karbala, Iraqi Geological Journal. 53 (1D): 17-25.

Aqrawi, A. A. M., Horbury, A. D., Goof, J. C., and Sadooni, F.N., 2010. The Petroleum Geology of Iraq. Seientific press Ltd, 424p.

Bellen, R. C., Van Dunnington, H. V., Wetzel, R., and Morton, D., 1959. Lexique Stratigraphique Internal Asie. Iraq. Intern. Geol. Conger. Comm. Stratigr, 3, Fasc. 10 a, 333 P.

Handhal, A. M., Al-Shahwan, M. F., and Chafeet, H. A., 2020. Interpretation of hydrocarbon generation, migration and thermal history of Mesopotamian Basin Southern Iraq based 1d Petromod software. Iraqi Geological Journal, 53 (1B): 29-56.

Ibrahim, M. W., 1983. Petroleum geology of southern Iraq. AAPG Bull., 67 (1): 97-130.

Idan, R. M., Salih, A. L., Al-Khazraji, O. N., and Khudhair, M. H., 2020. Depositional environments, facies distribution, and porosity analysis of Yamama Formation in Majnoon oilfield. Sequence Stratigraphic Approach, Iraqi Geological Journal, 53 (1D): 38-52.

Jassim, S. Z., and Goff, J. C., 2006. Geology of Iraq. Published by Dolin, Prauge and Moravian Museum, 341 P.

Jafar, M. S. A., 2001. Oil Habitat and Generation Times in Mishrif and Zubair Formations in Al-Zubair, West Qurna, North Rumaila, South Rumaila and Luhais oilfields-Southern Iraq. (ln Arabic), Unp. M. Sc. Thesis, University of Baghdad, 145 P.

Mohammed, A. K., Radhi, J. K., and Ali, S. Z., 2020. Well logs data prediction of the Nahr Umr And Mishrif formations in the well Noor-10, Southern Iraq, Iraqi geological Journal, 53 (2A), 2020: 50-67

Numan, N. M. S., 1997. A plate tectonic scenario for the Phanerozoic succession in Iraq. Journal of Geology, Society of Iraq, 30 (2): 85-110. 
OEC, 1987. Organic geochemical study of south and southeastern area of Iraq. OEC laboratories, Baghdad, Report number 56.

Owen, R. M. S., and Nasr, S. N., 1958. The stratigraphy of the kuwait-Basrah area in: habitat of oil: A symposium, Amer, Association of petroleum Geology, 1252-1278.

Sadooni, F. N., 1993. Stratigraphic sequence, microfacies and Petroleum prospects of the Yamama Formation, lower Cretaceous, Southern Iraq. AAPG Bull, 77 (11): 1971-1988.

Sharland, P. R., Archer, R., Casey, D. M., Hall, S. H., Heward, A. P., Horbury, A. D., and Simmons, M. D., 2001. Arabian plate sequence stratigraphy. GeoArabia special publication 2, Gulf petrol ink, Bahrain, $371 \mathrm{P}$.

Sofer, Z., 1984. Stable carbon isotope compositions of crude oils: application to source depositional environments and petroleum alteration. American Association of Petroleum Geologists Bulletin, 68: 31-49.

Turner, F. J., and Weiss, L. E., 1963. Structural Analysis of Metamorphic Tectonics. McGraw-Hill Book Co. Inc., New York, .205 P. 